\title{
Granulomatous arthritis in Crohn's disease
}

\author{
C. LINDSTRÖM, H. WRAMSBY, AND G. ÖSTBERG \\ From the University Department of Pathology, University of Lund, General Hospital, Malmö, and the \\ Department of Orthopaedic Surgery, Central County Hospital, Lidköping, Sweden
}

SUMMARY A case is described of non-necrotizing, epithelioid cell granulomatous synovitis of the ankle of a 22-year-old man with Crohn's disease. It appears to be the first published example of granulomatous arthritis in association with Crohn's disease.

Joint manifestations in Crohn's disease have been reported by earlier investigators. Crohn and Yarnis (1958) reported arthritis in $16(2.4 \%)$ of 676 patients with Crohn's disease and van Patter, Bargen, Dockerty, Feldman, Mayo, and Waugh (1954) found clinical affection of the joints in $4.5 \%$ of 600 cases. Such involvement of the joints may produce symptoms of the type occurring in polyarthritis or in ankylosing spondylitis with symptoms mainly in the knees, ankles, finger joints, or the vertebral column.

Histological examination of the synovial membrane performed in a few published cases of arthritis in patients with Crohn's disease has revealed nonspecific, inflammatory changes (Soren, 1966; Thayer, 1970).

\section{Report of a Case}

The patient was a 22-year-old man, who in 1967 (he was then 18 years old) developed clinical symptoms of Crohn's disease with the passage of watery and sometimes bloodstained stools and radiological changes in the distal ileum, caecum, and ascending colon (Fig. 1). He was treated conservatively with, among other things, Salazopyrin, and the symptoms regressed. In August 1968 he had a recurrence of severe diarrhoea with bloody stools. The radiological changes were mainly the same as one year previously. A tender, fusiform mass was palpated in the lower right part of the abdomen.

In November 1969 the patient became worse. He again had diarrhoea, later also with the passage of bloody stools. The symptoms responded well to Salazopyrin. At the last examination in August 1971 the intestinal disease appeared to be in a relatively quiescent stage.

The patient reported that in 1969 he had had a short attack of 'lumbago'.

Received for publication 25 January 1972.
Since the summer of 1970 the patient had had arthralgia and swelling of the right ankle. He could not remember any trauma or particular situation that might possibly explain the onset of the symptoms. In July 1971, after the symptoms had persisted

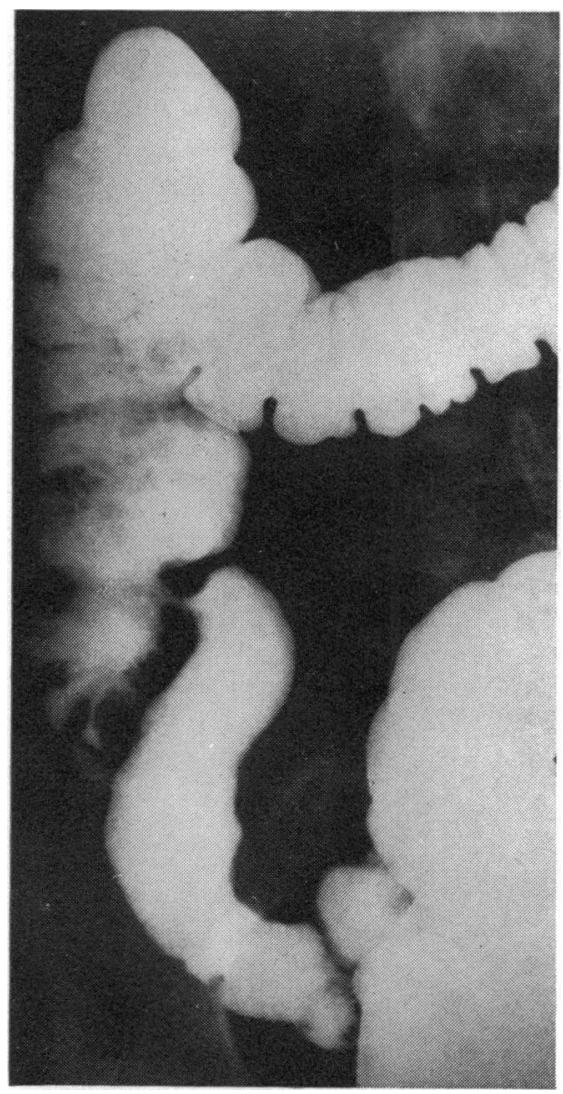

Fig. 1 Radiograph showing changes of Crohn's disease in the distal ileum, caecum, and ascending colon. 


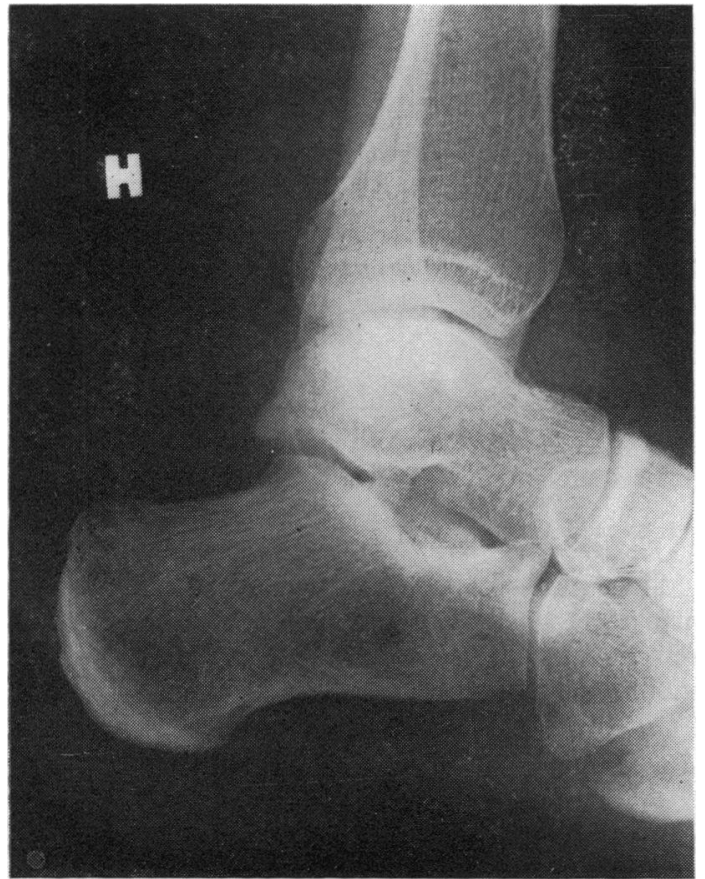

Fig. 2

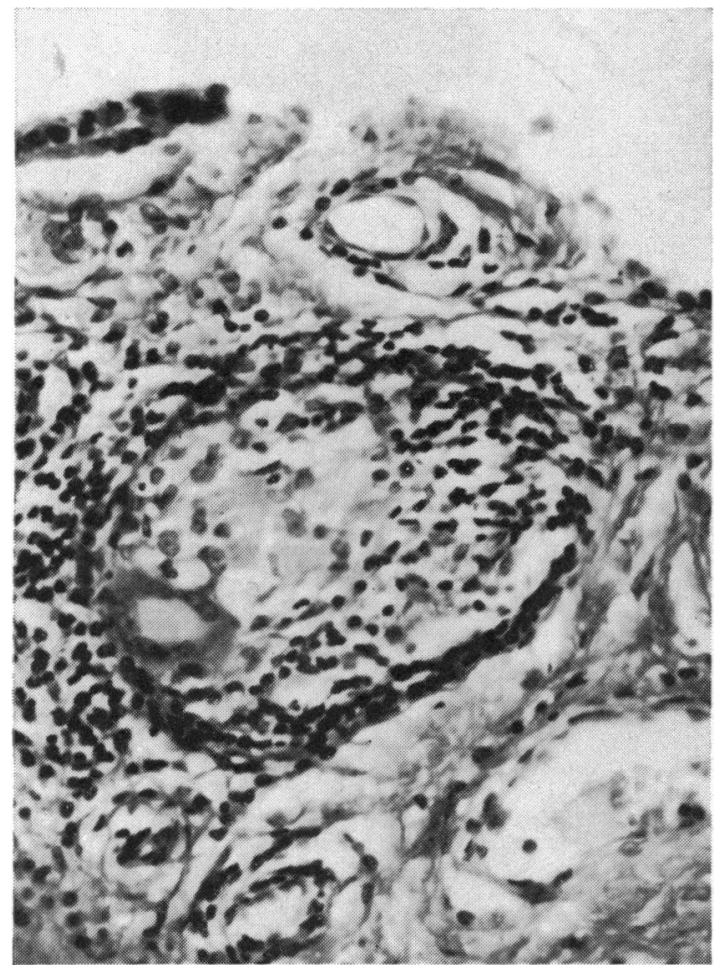

Fig. 4

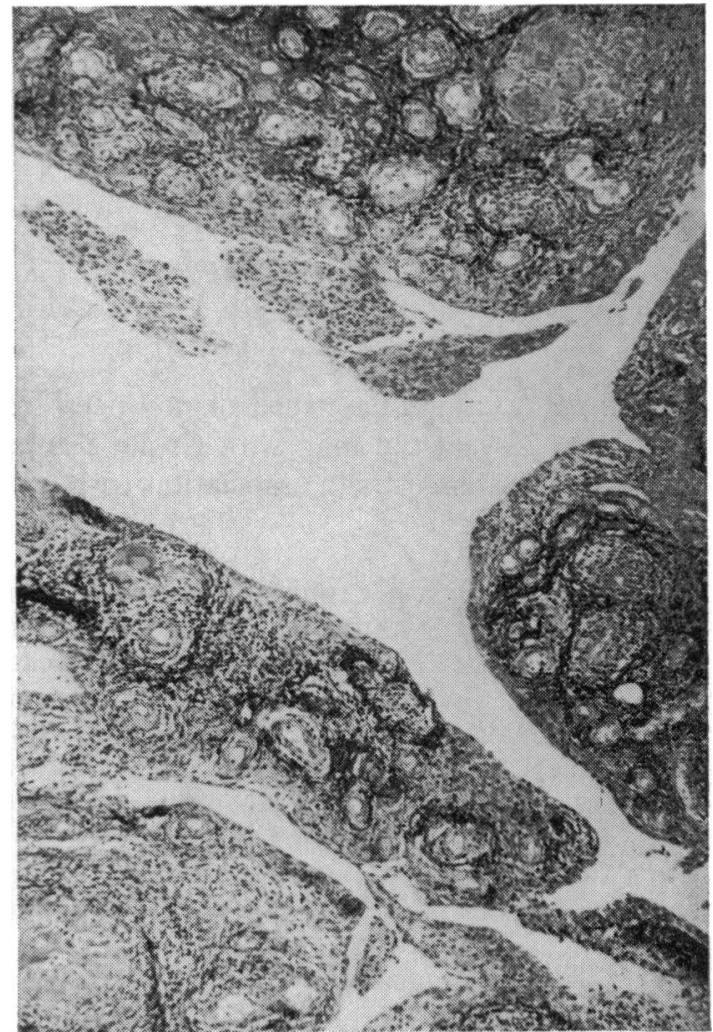

Fig. 3

Fig. 2 Radiograph of the right ankle.

Fig. 3 Histological picture of the synovial membrane with chronic inflammation and multiple epithelioid cell granulomas. van Gieson $\times 75$.

Fig. 4 Detail of epithelioid cell granuloma with giant cell of Langhan's type. van Gieson $\times 300$. 
for about one year, he was thoroughly examined and the area over the lateral malleolus was found to be tender to palpation and swollen. The swelling extended around the lateral malleolus towards the achilles tendon. Radiographs of the right ankle showed a piece of bone $5 \mathrm{~mm}$ long attached to the tip of the lateral malleolus and pointing towards the sole of the foot (Fig. 2).

The ESR was $17 \mathrm{~mm}$ in one hour. Since the RoseWaaler and the acrylic fixation tests were negative, and as the patient's history contained no note about any trauma, the right ankle was surgically explored. Operation revealed synovitis with granulation tissue in the ankle joint. The inflammation also involved the joint ventrolaterally to the talus. No ligamental injury could be found.

Histopathological examination of the synovial membrane showed chronic, granulomatous inflammation with hyperplastic mesothelium, lymphocytic infiltration, and multiple non-necrotizing epithelioid cell granulomas with giant cells of Langhan's type (Figs. 3 and 4).

No acid-fast rods were found in histological sections and neither direct microscopic examination of joint fluid nor culture for bacteria revealed any evidence of specific inflammation.

Specimens of synovial membrane gave a negative result on Löwenstein and guinea-pig culture tests. When the patient was 8 years old he had been BCG vaccinated; the tuberculin test was now positive.

Chest radiographs showed no signs of tuberculosis or sarcoidosis.

\section{Discussion}

In published series of arthritis of peripheral joints in patients with Crohn's disease the symptoms have been confined mainly to the knees and ankles and sometimes to the finger joints with subacute mi- grating asymmetrical polyarthritis (Ansell and Wigley, 1964; Wagner, 1969; Thayer, 1970; Brom, Bank, Marks, and Cobb, 1971).

In a few published cases of arthritis in patients with Crohn's disease in which the joints affected were examined histologically, the examination revealed only non-specific synovitis resembling that seen in arthritis in patients with ulcerative colitis (Bywaters and Ansell, 1958; Soren, 1966).

In the case under discussion there was thus chronic synovitis with multiple non-necrotizing epithelioid cell granulomas. It is, of course, not possible to conclude with certainty that there was any relationship between arthritis and the patient's intestinal disease, but the fact that the arthritis was confined to the ankle and that the joint symptoms appeared a few years after the onset of the intestinal disease make such a correlation very probable.

The occurrence of an epithelioid cell granulomatous synovitis in a patient with Crohn's disease may perhaps contribute to a wider conception of the pathogenesis of the intestinal disease and of its possibly systemic nature.

\section{References}

Ansell, B. M., and Wigley, R. A. D. (1964). Arthritic manifestations in regional enteritis. Ann. rheum. Dis., 23, 64-72.

Brom, B., Bank, S., Marks, I. N., and Cobb, J. J. (1971). Periostitis, aseptic necrosis, and arthritis occurring in a patient with Crohn's disease. Gastroenterology, 60, 1106-1109.

Bywaters, E. G. L., and Ansell, B. M. (1958). Arthritis associated with ulcerative colitis. A clinical and pathological study. Ann. rheum. Dis., 17, 169-183.

Crohn, B. B., and Yarnis, H. (1958). Regional Ileitis, 2nd ed. Grune and Stratton, New York and London.

Soren, A. (1966). Joint affections in regional ileitis. Arch. intern. Med., 117, 78-83.

Thayer, W. R. Jr. (1970). Crohn's disease (Regional enteritis). A look at the last four years. Scand. J. Gastroent., 5, Suppl. 6, 165-185.

Van Patter, W. N., Bargen, J. A., Dockerty, M. B., Feldman, W. H. Mayo, C. W., and Waugh, J. M. (1954). Regional enteritis. Gastroenterology, 26, 347-450.

Wagner, A. (1969). Arthralgien und Ileosakralarthritis bei Enteritis regionalis. Dtsch. med. Wschr., 94, 13-17. 